\title{
Student Collaboration in Faculty Development: Connecting Directly to the Learning Revolution
}

\author{
Milton D. Cox \\ Miami University \\ D. Lynn Sorenson \\ Brigham Young University
}

Although faculty developers bave worked successfully with faculty to focus on ways to enhance learning and listen to student voices, developers have rarely formed partnerships with students. This chapter reviews established practices involving students directly in faculty development, such as student observer/consultant programs. It also describes the nature, dynamics, and outcomes of some interesting new programs involving students in teaching development activities, thereby empowering students to join developers as change agents of campus culture. Finally, this chapter raises issues for faculty developers to reflect on as they consider establishing direct connections-partnerships-with students.

WYithin higher education for the last 15 years or so, there has been an $W$ increasing interest in, discussion about, and movement toward a focus on student learning. Faculty developers have been attuned to this movement. For example, Cross (1987) called for individual faculty members to study student learning in their classrooms and courses, and this quickly gave rise to classroom research projects coordinated by faculty developers (Erickson \& Erickson, 1988). Angelo (1989) proposed making "the 1990s the decade of faculty development for learning" (p. 37) but 
noted, as one obstacle, that " $[\mathrm{m}]$ ost faculty development programs focus primarily on teaching and secondarily on learning" (p. 43). In his article about future theories that will underlie faculty development, McKeachie (1991) states, "As I see it, the dominant theories deal with students. Our focus has shifted from instructional materials to faculty and now toward students" (p. 6).

In this decade, some have called this movement a paradigm shift from the old teaching paradigm to the new teaching paradigm (Johnson, Johnson, \& Smith, 1991) or from the instruction paradigm to the learning paradigm (Barr, 1998; Barr \& Tagg, 1995). In the first paradigm, knowledge is seen as transferred from faculty to students primarily through lecturing, while in the second, knowledge is jointly constructed by students and faculty through active learning. The first is teacher centered, and the second is student centered.

At the 1993 POD Conference, Zahorski exhorted:

If students are truly at the heart of the learning process and if we really empower them-shouldn't they be actively involved in our faculty development programs? If we don't involve them, are we neglecting one of our most important resources? Indeed, do we have an ethical obligation to involve our students more actively (1993)?

As noted by Sorenson (1994), "In citing student-centered pedagogies, the empowerment of students, learning partnerships, and the student as ultimate beneficiary of faculty development, Zahorski implored faculty developers to make sure the rhetoric actually reflects the reality" (p. 97).

Usually instructional developers work directly with faculty and TAs to enable better teaching and consequently enhance student learning. Other than students' occasional memberships on advisory boards, these practices do not often involve undergraduates directly as members or consultants of the faculty development office, the teaching and learning center, or programs coordinated by these offices. Instead, developers connect with faculty, who then connect with students. Within the teaching paradigm, these practices are usually successful. For example, with respect to developer consultation with faculty about student evaluations, "the reason that student feedback plus skillful consultation often leads to instructional gains is that the consultant is able to interpret student ratings in specific behavioral terms and to recommend specific behavioral change strategies" (Seldin, 1997, p. 339). As another example, developers 
working with faculty also have played key roles in faculty adoption of new ways to enhance learning, such as active learning, new technology, and classroom assessment techniques (CATs) (Richlin, 1998; Steadman, 1998). To illustrate, CATs (Angelo \& Cross, 1993) provide instructors with immediate student feedback on learning and, as it turns out, also enhance student learning (Cottell \& Harwood, 1998; Steadman \& Svinicki, 1998).

On the other hand, in the small group instructional diagnosis (SGID) process developed at the University of Washington in the 1970s (Redmond \& Clark, 1982), faculty developers work directly with students. After consulting with the instructor to determine course objectives and concerns, the instructional consultant dialogues with students in the class-the instructor is not present-to coordinate small-group discussions and report students' responses to two questions:

1) List the major strengths in this course. (What is helping you learn in the course?) Please explain briefly or give an example for each strength.

2) List changes that could be made in the course to assist you in learning. Please explain how suggested changes could be made. (Black, 1998, p. 247).

Afterwards, the developer shares the responses with the instructor, who then discusses the results and any changes with the class in the next class meeting.

Involving students directly in faculty development usually has been overlooked as a component of faculty development practices. Wright and O'Neil $(1994,1995)$ surveyed key instructional developers at institutions in the US, Canada, the UK, and Australasia; respondents rated the potential of 36 practices to improve teaching at their respective institutions. Practices that involve students directly are not on this list. Other surveys (Centra, 1978; Erickson, 1986; Kurfiss \& Boice, 1990; Chism \& Szabó, 1996) also have not mentioned involving students (although Kurfiss and Boice did include SGID as a "practice for scrutinizing teaching"-it ranked 5/6). The omission of these practices from faculty development indicates that involving students directly in faculty development has not only been just a small component of faculty development practices-it has been virtually invisible.

Has there been a revolution this decade in faculty development practice and organization with respect to student learning and involvement? 
This article reviews established practices that faculty developers are coordinating that involve students directly with the faculty development office, such as student observer/consultant programs. It also describes the nature, dynamics, and outcomes of some interesting new programs and raises issues for faculty developers to reflect on as they consider establishing direct connections-partnerships-with students in this learning revolution.

\section{Student Observer/Consultant Programs}

Just as the classroom research movement has provided college teachers with CATs for feedback on their students' perceptions and learning, student observer/consultant programs provide authentic student perspectives that connect faculty to students and enhance learning.

Serving as an introduction to formative evaluation, the student consultation model opens dialogue about teaching, learning, course design, and other important educational issues. Trained students attend class and consult with instructors. Their feedback catalyzes improvements in pedagogy, classroom climate, and course policies. As a result of participating in a student observer program, faculty may welcome observers (even peers) and become champions for "chang[ing] the status of teaching from private to community property" (Shulman, 1993, p. 6). In addition, student observer/consultant programs help connect participating faculty with important campus resources, such as media services and the center for teaching.

The following institutions have sponsored student observer/consultant programs: Carleton College; St. Olaf College; Brigham Young University; University of Chicago; DePauw University; Rutgers, The State University of New Jersey (Camden); University of Arizona; University of Illinois (Springfield); Indiana State University; Pennsylvania State University; University of Toledo; University of Georgia; and Worcester Polytechnic Institute. Some of these institutions are not currently sponsoring programs; some have provided these services for decades; and others have initiated programs only recently. The diversity of institutions sponsoring these programs ranges from private liberal arts colleges to public Research I universities. As these programs expand into an ever-increasing variety of institutions, questions regarding their viability in diverse settings (Sorenson, 1994) have been answered in the affirmative.

Despite the widespread popularity and effectiveness of these programs, an occasional skeptic will protest, "How can they help faculty? 
They are just students!" That is exactly their strength; they are students. Of course they are not experts on content; that sort of formative evaluation is better left to faculty and disciplinary peers. But as students, they are experts-in their own way-about sitting in classes, doing assignments, preparing for tests, etc. For years, they have participated in dozens of classroom experiences-some of which are conducive to learning and some of which are not; that is why their voices, their views, and their perspectives are imminently valuable.

\section{Options for Faculty: Ways to Use Student Observers/Consultants}

What is it that student observers/consultants do in the classroom? The Faculty Center at Brigham Young University (BYU) sponsors a nineyear-old program, Students Consulting on Teaching (SCOT) (previously known as the Classroom Student Observer Program). Faculty select the services they want from various options. Information about the SCOT program, including the following list of ways to use SCOT (Sorenson, 1999), appears on the BYU Faculty Center web site at www.byu.edu/fc.

Recorder/observer. The student consultant records in writing what went on in the class (e.g., chronology of classroom activities, time spent in questioning, board work, small-group discussion, etc.) and gives the record to the instructor. The observer describes rather than evaluates.

Faux student. The student observer/consultant takes notes as if she or he were a student in the class and returns them to the instructor.

Videotaper. The student observer/consultant videotapes the class and gives the videotape to the instructor. The instructor may invite the SCOT to watch and discuss the videotape.

Interviewer. The instructor leaves the classroom for 15 minutes while the student consultant interviews class members about their learning in the course, as in the SGID method mentioned earlier. (This option is by far the most popular one used by instructors at BYU.)

Primed student. The student observer/consultant meets with the professor prior to class to discuss what to watch for, such as: how often certain kinds of students respond (e.g., women/men, minority/majority, traditional/non-traditional), how to involve more students in discussion, what students are doing while the instructor is manipulating a PowerPoint presentation, whether students are on task during small-group work, etc.

Student consultant. The instructor asks the student observer/consultant for evaluative feedback on classroom activities or on particular 
learning issues of concern. Based on this interaction, the instructor plans innovations, and the student consultant continues to provide feedback.

Otber. Other methods include CATs, beta-testing of web-based course modules, etc.

These options include a wide range of activities, from simple data gathering to "continuous quality" consultation. The list of options facilitates faculty entrance to this formative evaluation process without instructors having to invent some grand project for the student observer/consultant to perform. Faculty can receive custom-fit feedback without pleading, "I need help; come advise and consult with me." As trust develops between the instructor and the student consultant, they often initiate more extensive activities (like CATs) and/or explore resources (including meeting with the campus faculty developer) to address particular issues.

Approximately $13 \%$ of BYU instructors have participated in the SCOT Program. From fall semester 1992 through fall semester 1998, nearly $300 \mathrm{BYU}$ instructors used the program. About 400 classes have been observed, videotaped, interviewed, etc., affecting thousands of students. Nearly a quarter of the faculty participants are repeat users, and about half are newer faculty on their way to tenure. Both the number of participants and courses observed has increased each semester since the program began in 1990 .

\section{Managing a Student Observer/Consultant Program}

To initiate and manage a SCOT program effectively, consider the following aspects:

Program coordinator. A student observer/consultant program needs one person to oversee the logistics. This might be the campus faculty developer, a professor, a graduate and/or work-study student, or a student government leader. This person (or a chair/dean/administrator) invites faculty to participate via email, flyers, or letters. From that point on, the process is both self-selecting and confidential.

Student recruitment and remuneration. In terms of recruitment, Sorenson (1999) writes that "[observers/]consultants are carefully selected students who are interested in the teaching and learning process" (p. 1). The BYU program requires student consultants to have at least a 3.0 GPA and provide two recommendations, one of which must be from a professor. (The other may be from another teacher or an employer.) At BYU, student consultants are recruited at the beginning of both fall and winter semesters. 
Sources of potential SCOTs include education (and other) classes, student government and/or service organizations, faculty referrals, relatives/friends of current or past SCOTs, and articles in the student newspaper. At Carleton College the vast majority of student observers are majoring in educational studies (Morral \& Tonyan, 1995). The University of Chicago program was designed to employ only MBA students.

On some campuses, student observers/consultants participate in this kind of program as a service, much as they would tutor or serve as student government committee members. Other institutions employ a servicelearning model: students enroll in a credit-bearing class about teaching and learning, and their observations/consultations are part of their assignments for the class. The most common model is one in which students are paid hourly wages through student employment services or work-study programs. Nevertheless, students who participate in these programs usually value the intrinsic rewards more than the monetary ones: "Prof. XX was extremely interested in my ideas which was a valuable experience for me"; "I had a relaxed relationship with the teacher while feeling at the same time that he respected my [opinions]." Notice how validated these students feel when serving in this instructional/faculty development role.

Preparing and supporting student observers/consultants. The training of student observers/consultants can be as extensive as a semester-long course they take before or during their consultation work or as simple as a short orientation before they begin. At BYU, preparation and support consist of bi-monthly training meetings, mentoring of new consultants by "veterans," and consultation with the campus faculty developer. In addition, before a SCOT is hired, she or he must perform a prearranged "guinea pig" observation of a class and write a report, as if this were an officially assigned consultation. Copies of these reports are sent to the instructors who volunteered to be observed, but no actual follow-up meetings are held. Instead, experienced SCOTs role-play a "follow-up meeting with an instructor" for the prospective SCOTs; then each new SCOT practices a "follow-up meeting" with a veteran SCOT playing the part of an instructor. Training materials from most programs include copies of some observers' reports (without names and other identifying information) to serve as examples for novice observers.

Topics addressed in training meetings include one-on-one consultations, report writing, interview techniques, and topics from educational psychology such as Bloom's taxonomy (Harb, Hurt, Terry, \& Williamson, 1995). In addition, students are provided articles/monographs such as 
"Seven Principles of Undergraduate Education" (Chickering \& Gamson, 1987) and other teaching/learning resources. Many times the student consultants benefit most from group discussion about issues that have arisen in their consultations. A campus faculty developer or an education or psychology professor can serve as a ready resource to the student consultants.

Those considering implementing a student observer/consultant program need not be overly concerned about providing extensive training. The fact that the students are not accomplished experts on pedagogy is not a hindrance but, in some ways, an asset to the effectiveness of their feedback.

Promoting the service to faculty. Who are the clients/participants in these programs? According to the Carleton College handbook for student observers,

Users include faculty who are tenured and untenured, permanent and temporary. The program is used by people offering large lectures and small discussion classes, by faculty who are experimenting with something new or by faculty who simply want to ensure that their pedagogical methods are working (Morral \& Tonyan, 1995).

Many faculty members participate in these programs year after year (Sorenson, 1998a).

One of the attractions of these programs is that they are "faculty driven." In other words, instructors decide whether to use a program, when and how much to use it, what options to use, and when to terminate. In addition, the data gathered is for the instructors' benefit. They decide what impact that data will make on their course design and course activities.

The promise of confidentiality is inviting to faculty who are considering participation in these programs. According to the Rutgers-Camden web site materials,

Confidentiality is the watchword in this ... program. ... The results are strictly between [the instructor] and the student observer.... [N]o one outside [the teaching and learning center] knows that the professor is involved in the program at all (Omaha Boy, 1998, paragraph 6).

These assurances of both choice and confidentiality encourage faculty participation. 
Although these observations, consultations, and reports are components of formative evaluation, some faculty members choose to display them as part of a teaching portfolio for summative evaluation. They may include student consultants' reports, the plans they developed as a result of the student consultation, and subsequent learning outcomes-but only at the faculty member's discretion and only as part of a portfolio that includes a variety of materials (e.g., student evaluations, peer reviews, syllabi, student products).

\section{Outcomes}

Student consultant programs allow faculty and student observers to experience new kinds of interactions-interactions that, among other things, value the student voice in faculty/instructional development (Sorenson, 1998b). Based on student consultants' feedback and advice, faculty often make changes. For example, instructors report modifications as simple as "speaking more loudly" or "writing more legibly on the board." Others implement more significant innovations, such as "initiating role plays" and reviewing before class "a list of things that intimidate students" in order to avoid those counterproductive behaviors. One teacher of Portuguese wrote:

[As a result of student observations and consultations], I developed a system wherein I include student presentations along with a teaching cycle that involves a practice session after every ... concept. [Now] the time I spend giving instruction [has] decreased to under 20 minutes, while the students' practice time [has] increased to $30+$ minutes. My students [learn at] a higher mastery level. I [intend to] continue [this] in the future.

When faculty implement changes as a result of student observations/consultations, enrolled students report enhanced learning and greater teacher approachability (Sorenson, 1998a). In addition, student observers/consultants "understand more about how professors prepare, evaluate, and refine a course, [and they] gain more of a faculty perspective on how the teaching process continues throughout a course" (Morral \& Tonyan, 1995). One experienced student observer stated, "I learned a lot about effective teaching and communication between a teacher and his or her students."

Through their participation in these programs, many student consultants experience personal growth: "I learned how to give constructive 
feedback"; "l'm developing person-to-person skills"; "This [experience] was valuable because it helped me learn a different, but effective style of teaching"; "I saw and learned a lot of different teaching techniques. I was able to learn how to communicate better with a professor." Consulting students feel productive when they see the positive effects of their efforts. One student reported, "I was able to see a professor [make use of] the results [of the interview]; he took notes and picked out 3-4 things to work on."

\section{Evaluation}

At the conclusion of their consultations, both SCOTs and instructors are invited to evaluate their collaboration by responding to a questionnaire in which they identify both the strengths and limitations of the program and their own interactions in the program. Nine years of evaluation data about BYU's program reveal consistently positive attitudes, interactions, and outcomes. A student observer reported, "I gained a great deal from seeing both the perspective of the teacher and the students."

Student observer/consultant programs honor both the student voice and faculty desire to enhance the learning of their own students. One elementary education professor wrote: "[SCOT helped me] improve! Great feedback and encouragement! [The student consultants] were genuine and sincerely interested in me [and my students]." A public management professor lauded the program for adding "a new dimension to the evaluation process." A music professor reported: "I have had student consultants videotape, observe, and interview students in two of my classes. I have found their assistance almost priceless in learning from my mistakes and building on my strengths as a teacher. [This program] is very conducive to improving the quality of teaching." In fact, not only do these programs improve the quality of teaching and enhance learning, they also build a campus-wide community (including students) that addresses important issues in teaching and learning.

\section{Faculty Development Seminars Involving Students}

In order to encourage faculty and student learning partnerships and faculty interest in student learning, developers have coordinated seminars and workshops about students. For example, Rallis (1994) describes a workshop in which faculty discuss their students' pet peeves about college instructors-concerns that were collected from a survey of students. One workshop outcome is that instructors develop a plan to change their 
teaching, for example, organizing course material in a variety of ways to honor different learning styles. However, because students do not participate in these seminars, their immediate reactions, feedback, and learning are lost. What if they did participate in such a seminar?

\section{The Joint Student-Faculty Seminar on Sharing Views of Teaching and Learning}

An example of a successful joint student-faculty venture coordinated by a faculty development office is the dinner seminar "Sharing Faculty and Student Views of Teaching and Learning." It has taken place for 10 years as part of Miami University's Teaching Scholars Program, a year-long faculty teaching development program for junior faculty in their second through fifth years of teaching (Cox, 1994, 1995). Each of the 11-14 junior faculty participants invites a student to attend and help prepare for the two-hour seminar. The selection of students is not limited in any way; they may be first-year through graduate, either traditional or nontraditional, from all campuses, and having various grade point averages. Most are undergraduates of traditional age and articulate-willing to speak out.

The program coordinator sends faculty participants a seminar information request form (see Appendix 1) beforehand, which asks them to list their " 5 keys to successful teaching" as viewed by faculty. The students are sent a similar form asking them to list " 5 keys to successful teaching" as viewed by students (the student form is the same except it is titled "Student Responses"). Each faculty member also writes two "questions to students about teaching and learning," and each student writes two "questions to faculty about teaching and learning." Both faculty and students identify a metaphor for teaching and learning.

The seminar coordinator compiles the open-ended responses, then sorts the keys by general categories and indicates the frequency of faculty and student responses in each category (see Appendix 2). (For a synthesis of 31 similar studies in which student and faculty views of effective teaching were compared, see Feldman (1988); however, only 2 of the 31 studies involved open-ended responses.) The lists of questions (see Appendix 3), keys, and metaphors are distributed to all participants before the seminar.

The seminar begins with student and faculty introductions, followed by discussion about the difference between types and frequencies of keys to successful teaching as listed by faculty and students. For example, in Appendix 2, contrast the faculty-to-student ratio of 1:2 (4 responses:8 
responses) in the category of "student relations/rapport" with the ratio of 2:1 on "concrete-in-class/out-of-class activity/process." Note that in the latter category three students think teaching to a variety of learning styles is an important key, while no faculty have listed this key. Another interesting observation is the large number and variety of keys appearing on both lists. Of the 33 faculty and 31 student keys, 14 (42\% and 45\%, respectively) appear on both lists. These observations start a lively discussion that goes for 15 minutes or so, followed by 45 minutes of conversation alternating between student questions and faculty questions. A nice dinner (particularly to thank the students) - but a working dinner-then occurs with small-group discussion.

The usual outcome of this seminar is an increased understanding of each other's perspectives. For example, students discover how much care, interest, and fervor these faculty devote to their teaching, and they learn about other university demands on faculty time. Faculty learn about students' understanding and confusion regarding liberal education objectives, frustrations with certain teaching styles (e.g., "Why are all my instructors trying cooperative learning?"), and the variety of demands on student time.

After the seminar, each student receives a thank-you letter from the program director, and both faculty and students receive seminar evaluation forms. Out of the dozen or so seminars sponsored by the program over the year, faculty rate this seminar at or near the top when asked, "How interesting did you find this seminar?" For example, in 1996-97 this seminar received the highest rating out of all seminars (see Figure 7.1).

One factor cited for the success of the seminar is the scholarly and open climate of the proceedings. One student wrote:

I thought the professor-student interaction was good-everyone respected everyone else's opinions-even when there were distinct disagreements. The format worked well: by having discussion first, grounds were laid for small group discussion during dinner. Overall I am happy I was able to participate in this seminar.

Another year-long Miami faculty learning community sponsored by the development office, the Senior Faculty Program for Teaching Excellence (Cox \& Blaisdell, 1995), also has adopted this seminar. The procedure and format are the same. However, the types and frequencies of keys 
Figure 7.1

Seminar Interest Ratings for Miami's Teaching Scholars Program

( 0 denotes low interest, 4 denotes high interest)

\begin{tabular}{|l|l|}
\hline Rating & Seminar Type \\
\hline 3.6 & Sharing faculty and student views of teaching and learning \\
3.5 & Diversity issues and opportunities in teaching and learning \\
3.4 & Teaching goals inventory and CATs \\
3.4 & Ethical dilemmas in teaching \\
3.3 & Cooperative learning \\
3.1 & Student intellectual development \\
2.9 & All about mentors \\
2.9 & Scholarship of teaching \\
2.9 & Teaching projects: Selected, in-depth reports \\
2.7 & Learning disabilities \\
2.7 & Obtaining feedback from students \\
2.4 & Service learning \\
2.0 & Assessment: Meeting course and long-term learning objectives \\
\hline
\end{tabular}

can vary. For example, the 1998 senior faculty seminar with students revealed fewer keys appearing on both lists (29\% and 33\%, respectively) and different categories with unbalanced ratios (the faculty:student ratio is 1:2 in "professor knowledge/skill" and 3:1 in "abstract (less concrete) inside/outside class procedures").

\section{Students as Chairpersons of Faculty Development Seminars}

Another way to involve students in faculty development seminars is to have them chair sessions that the faculty development office or teaching center coordinates. This student involvement can assist the teaching center when several concurrent sessions occur during campus conferences or retreats. At Miami, both faculty and students have been pleased with this involvement.

A protocol for students chairing sessions has been developed over the years (see Appendix 4). The office holds a one-hour "training session" a week or so before the event. Students can receive hourly wages for their involvement in training and the seminar. Some student service organizations have their members participate as a group, with their earnings going to the organization.

This experience provides a scholarly way for faculty developers to 
connect directly with students. As one student reported in a reaction paper about her experiences chairing a session:

Overall, I found the experience to be very enlightening. I was able to compare the different styles of teaching in all my classes to what [the professor] talked about. It made me grateful to know that so many teachers were actually concerned about their students.

\section{Students as Professional Critics}

The following innovative project illustrates yet another effective way to involve students in faculty development seminars. After a major science curriculum redesign at an eastern university, summer workshops were designed to prepare 25 instructors to teach new content to different students using new methods-different and new in the sense that these instructors had not experienced these situations before (Herreid \& Kozak, 1995). During the first week of the program, the instructors attended seminars on student learning, such as Kolb's learning styles, and ways to use new approaches, such as case studies. During the second and third weeks, instructors developed syllabi and presentations. In the last week, the instructors delivered at least one class presentation to a group of students who had been hired to serve as critics. These 16 junior and senior undergraduates were representative of the student population (with respect to gender and ethnicity), had a wide range of grade point averages, and were majoring in 12 different disciplines in the humanities and social sciences. The students were selected from those responding to an ad in the student newspaper.

Both faculty and students were enthusiastic about the experience and recommended that it continue. Evaluations and resulting practice indicate that faculty gained a better sense of how they teach and the students of how they learn. For example, the use of small groups was carefully tried, the results analyzed, and the method adopted by many participants. Both faculty and students learned ways to communicate across very different disciplines, and they gained respect for one another.

\section{Students as Members of Faculty Learning Communities}

Learning communities provide excellent opportunities for students to learn, and learning communities of faculty are no exception. This section 
examines an attempt to involve students in faculty learning communities directed by faculty developers.

This is the 20th year of the Teaching Scholars Program, a learning community of junior faculty at Miami University. One of the key features of the program has been the involvement of senior faculty mentors (Cox, 1997a). Although students are members of the program's advisory committee, it was not until the 18th year of the program that the idea occurred to the director that student consultants or associates might also play an important role in actually working with junior faculty. The involvement of student consultants was also introduced in Miami's Senior Faculty Program for Teaching Excellence (now in its 8th year).

The objective of including student consultants in these two programs is to enhance the likelihood of achieving these program goals:

- Enhancing interest in teaching, teaching effectiveness, and student learning, for both faculty and students

- Advocating and developing educational and pedagogical innovation

- Interacting as an interdisciplinary community

- Discovering and incorporating ways that difference can enhance teaching and learning

Because Miami does not have a student observer/consultant program, faculty program participants select students to work with them much as the junior faculty select their senior faculty mentors (Cox, 1997a). Faculty usually invite students who have been in their past classes or are majors in their disciplines.

The program allows each faculty participant to involve his or her student consultant in joint activities similar to those described previously in the section on student observer/consultant programs. Activities can also be specific to the faculty member's participation in the Teaching Scholars or Senior Faculty Program. These joint activities include attendance at program seminars, work on the faculty participant's teaching project, and reading articles in preparation for a seminar. Members of both groups are now investigating the possibility of trying "team teaching with a student" (Gray \& Hulbert, 1998).

The following guidelines about student consultants were adopted by both programs.

- Each participant selects one or two student consultants each semester. The student can be of any class standing or major. If a faculty 
participant selects a graduate student, then in order to ensure broad perspectives, he or she also selects an undergraduate.

- The faculty participant's role is twofold, as learner and as teacher. Faculty will learn from their students' perspectives, and students will learn about professorial life and the academy.

- Consultations between faculty participants and students is scheduled at least twice a month. Informal discussion includes, for example, classroom observations, topics raised at seminars in the program, insights about the faculty member's teaching project, responses to an article, and reactions to innovations the faculty member is considering or implementing in his or her classes.

- Faculty participants usually do not select students enrolled in their current classes. Although this could provide ongoing topics for discussion and helpful suggestions, there are ethical considerations. For example, student or faculty perspectives could be biased by the current faculty-student relationship. Students from past classes are good candidates.

- Student consultants are encouraged to participate in some of the program's seminars, such as the joint faculty-student seminar discussed earlier.

- Students are encouraged to chair sessions at the Lilly Conference on College Teaching in November and at the campus-wide Teaching Effectiveness Retreat held at Miami in February.

- Students should be rewarded/reimbursed for serving. This also helps ensure that their commitments as student consultants will last throughout the semester. Some reward/reimbursement possibilities are as follows.

Undergraduate associates. The Undergraduate Associates Program (UAP) is administered by the University Honors Program. It gives a student consultant the opportunity to work closely with his or her faculty member to explore careers in academia. The UAP is open to juniors and seniors with strong academic records. In the UAP, a student works for a semester or a year with a faculty mentor assisting with many of the tasks addressed by academics (e.g., teaching, grading, attending governance meetings, engaging in research, etc.). A student completing the UAP and submitting a final report receives the notation "Undergraduate Associate" on his or her transcript. 
Independent study. Student consultants can earn an hour (or more) of independent study credit under the direction of their faculty program member.

Student wages. Faculty participants can arrange for the program to pay their students for serving as consultants. Faculty can also provide thank-you gifts (e.g., books, software) to their student consultants, purchased from program funds.

After a year and a half of piloting the use of student consultants in these two faculty learning communities, some short-term outcomes can be reported.

The senior faculty evaluations of the program report strong impact from involvement with their student consultants/associates. Each year the senior faculty participants report the relative impact of nine components of the program: release time, colleagueship and learning from the other participants, student consultants, the teaching project, retreats, national conferences, seminars, observation of others' classes, and partnership with a colleague in the program (Cox, Cottell, \& Gusthart, 1998). In 1997-98, the student consultant component was rated highest in impact with an 8.3 on a rating scale of 1-10. On the comments page of the evaluation, one senior faculty participant wrote:

This was one of the biggest surprises of last semester. My two student consultants were wonderful aides in helping me evaluate what was going right or wrong in the class. They developed a survey of the class, wrote up their own analysis, and met with me about five or six times to discuss teaching methods. I thoroughly enjoyed the group session with all the student consultants at the end of last semester. I plan to have a similar experience with two consultants (I think more would be too many) this semester.

The junior faculty, on the other hand, rated the impact of the student consultant/associate component last out of eight program components, giving it a 5.0 on the same scale as above. The junior faculty reported that their contacts with students suffered because of the following difficulties: identifying students to work with, students not following through on plans, students backing out (too busy), conflicting schedules, lack of time to meet, etc. At the midpoint of 1998-99, the evaluation results reconfirm those of 1997-98.

The impact of student consultants on junior and senior faculty differs for the following reasons. Senior faculty are experienced and familiar 
with campus culture, well acquainted with students in their departments, effective in motivating and rewarding student participation, and do not have the pressures of obtaining tenure. Junior faculty are at a disadvantage since there is no student observer/consultant program on campus to provide the structure for the junior faculty-student connection. Thus, the student consultant component will probably become optional for junior faculty, available for those who wish to invest the time to reap the advantages of consulting with students.

\section{Involved Students: Potential Change Agents}

Students are potential agents for change of campus culture. For example, they can help facilitate the shift from the teaching to the learning paradigm. Such a change can be a result of their faculty development activities as student consultant/observers, as professional critics, as leaders of or participants in faculty development seminars, and as members of advisory committees for faculty development programs.

Faculty developers and college teachers can go beyond just involving students in faculty development practices. When students reflect and write about their faculty development experiences, it enhances their involvement by deepening their learning and growth, and it also provides helpful feedback to developers. A reflective approach could include student reaction papers, journals, and other ways of prompting student reflection on the experience. Cox (1997b) offers this as a student portfolio option in his undergraduate mathematics courses. The following examples from these portfolios illustrate students reaching beyond their faculty development activities to affect other parts of campus.

In the excerpt below from a student reaction paper, a junior, who served as chair of a faculty development seminar, learns and then becomes an advocate for broader evaluation in his division:

The first presentation I saw ... was on peer evaluation of teaching. As [the presenter] began to talk about the literature on the subject, I realized how important it was. I've spent over two years participating in the governing bodies [in my division] with various faculty members, and have engaged in several conversations on the use of student evaluations. But we never once discussed the concept of being evaluated by peers. It seems that this could be an effective means of legitimizing the teaching process in the 
university. A faculty member may prove to be very knowledgeable about a given subject or topic, but his/her effectiveness as a teacher is a completely separate question.

Another student writes about her reactions as an active participant in a faculty development diversity seminar. She has grasped the complexity of adopting the learning paradigm but needs encouragement to persist in finding ways that she can support change.

Upon looking at my newly acquired knowledge from the Diversity Seminar, I am now realizing how few of my classes incorporate inclusive teaching and learning in the curriculum. Diversity is not emphasized in the classrooms at Miami, thus the University as a whole is also having problems making the campus a diverse environment. From what I have gathered, it is necessary to start at the bottom and work your way up, so perhaps by beginning with a change in teaching styles and curriculum to add diversity, eventually it would flow to the entire campus. All of the things that would diversify the curriculum are great ideas, and from a student's view, would add new and interesting aspects to the classroom while giving new perspectives on the traditional information. Unfortunately, though, all these educationally stimulating ideas would be extremely time consuming for the individual departments, the professors, and the university as a whole to accomplish if the final goal was a complete transformation of the system.

The Oslo College Centre for Staff and Learning Development provides an excellent model for examining the issues, determining strategies, and establishing practices designed to form partnerships with students (Havnes, 1998). This is accomplished by creating contexts for educational development. Havnes examines a theoretical platform ${ }^{1}$ for developing partnerships with students and concludes, "Changing cultures is basically what we are talking about when we discuss the opportunities of making students partners in the educational process-changing cultures among [faculty], among students, and in the relationship between [faculty] and students" (p. 9). He goes on to say that to effect this change, there will be disequilibria that threaten the existing system and challenge traditions of both teachers and students. He then asks, "Are educational developers prepared to meet this challenge?" (p. 9). Faculty developers in 
partnerships with students can help prepare the university community for this discussion and facilitate the shift to the learning paradigm.

\section{Issues to Consider}

The following questions will guide faculty developers considering student partnerships on their campuses:

- What goals and objectives of faculty development can students contribute toward achieving?

- How and in what ways are students qualified to serve?

- How does one initiate student involvement in faculty development programs?

- How are students identified, selected, and rewarded each year for participating in faculty development efforts?

- What are effective ways to collaborate with students in this role?

- How do faculty react to student involvement?

- How do students react to participating in faculty development?

- What ethical concerns are involved?

- How can the effectiveness of student involvement be measured?

- How can faculty developers foster connections with their student affairs divisions, and what joint efforts and objectives can be achieved?

- How can partnerships developed with students foster the transformation to the learning paradigm?

Some of these questions have been addressed in this article, but because of the diversity of campus cultures and their faculty development offices, programs, and staff, there will be a rich variety of interests, needs, strategies, and activities generated by these questions.

In the 1990s, faculty development practice has been successful in enabling faculty to focus on learning. However, "revolutionary" faculty development partnerships with students await the next decade. To transform higher education from the teaching paradigm to the learning paradigm, it is now time to examine these issues seriously and consider ini- 
tiatives to form partnerships with undergraduates. They join together with graduate students, faculty, administrators, and developers, as learners, observers, consultants, critics, participants, advisers, associates, and leaders in educational development.

\section{ENDNOTES}

'Havnes' theoretical platform examines four approaches: the theory of levels of learning, in B. Bateson (1992), Steps to an ecology of mind (Canada: Ballentine Books); the zone of proximal development, in Vygotsky (1978), Mind in society: The development of higher psychological processes (M. Cole, V. John-Steiner, S. Scribner, \& E. Souberman, Eds.; Cambridge, UK: Cambridge University Press); activity theory, in Engeström (1987), Learning by expanding: An activity-theoretical approach to developmental research (Helsinki: Orienta-Konsultit $O y$ ); and the community-of-learners model, in Rogoff (1994), Developing Understanding of the Idea of Communities of Learners, Mind, Culture, and Activity, 1 (4), 209-229.

\section{REFERENCES}

Angelo, T. A. (1989). Faculty development for learning: The promise of classroom research. To Improve the Academy, 8, 37-60.

Angelo, T. A., \& Cross, K. P. (1993). Classroom assessment lechniques: $A$ handbook for college teachers. (2nd ed.). San Francisco, CA: Jossey-Bass.

Barr, R. B. (1998). Obstacles to implementing the learning paradigm-What it takes to overcome them. About Campus, 3 (4) 18-25.

Barr, R. B., \& Tagg, J. (1995, November/December). From teaching to learning-A new paradigm for undergraduate education. Change, 27 (6), 13-25.

Black, B. (1998). Using the SGID method for a variety of purposes. To Improve the Academy, 17, 245-262.

Centra,J. A. (1978). Types of faculty development programs. The Jourmal of Higher Education, 49 (2), 150-161.

Chickering, A. W., \& Gamson, Z. F. (1987). Seven principles for good practice in undergraduate education. $A A H E$ Bulletin, 39, 3-7.

Chism, N. V. N., \& Szabó, B. (1996). Who uses faculty development services? To Improve the Academy, 15, 115-128.

Cottell, P., \& Harwood, E. (1998). Do classroom assessment techniques (CATs) improve student learning? In T. A. Angelo (Ed.), Classroom assessment and research: An update on uses, approaches, and researcl findings (pp. 37-46). New 
Directions for Teaching and Learning, No. 75. San Francisco, CA: JosseyBass.

Cox, M. D. (1994). Reclaiming teaching excellence: Miami University's Teaching Scholars Program. To Improve the Academy, 13, 79-96.

Cox, M. D. (1995). The development of new and junior faculty. In W. A. Wright \& Associates (Eds.), Teaching improvement practices: Successful strategies for bigher education (pp. 283-310). Bolton, MA: Anker.

Cox, M. D. (1997a). Long-term patterns in a mentoring program for junior faculty: Recommendations for practice. To Improve the Academy, 16, 225-268.

Cox, M. D. (1997b, October). Student learning portfolios/faculty teaching portfolios: Alook at each from both sides, now. Paper presented at the Lilly Conference on College and University Teaching, Northwest, Portland, OR.

Cox, M. D., \& Blaisdell, M. (1995, October). Teaching development for senior faculty: Searching for fresh solutions in a salty sea. Paper presented at the Conference of the Professional and Organizational Development Network in Higher Education, North Falmouth, MA.

Cox, M. D., Cottell, P., \& Gusthart, J. L. (1998, October). Student collaboration in faculty development: Connecting directly to the leaming revolution. Paper presented at the Conference of the Professional and Organizational Development Network in Higher Education, Snowbird, UT.

Cross, K. P. (1987). The need for classroom research. To Improve the Academy, 6, 3-17.

Erickson, G. (1986). A survey of faculty development practices. To Improve the Academy, 5, 182-196.

Erickson, B. L., \& Erickson, G. R. (1988). Notes on a classroom research program. To Improve the Academy, 7, 19-22.

Feldman, K. A. (1988). Effective college teaching from the students' and faculty's view: Matched or mismatched priorities? Research in Higher Education, 28(4), 291-344.

Gray, T., \& Hulbert, S. (1998). Team teach with a student. College Teaching, 46(4), 150-153.

Harb, J. N., Hurt, P. K., Terry, R. E., \& Williamson, K. J. (1995). Teaching through the cycle. Provo, UT: Brigham Young University Press.

Havnes, A. (1998, April). Students as partners in educational development-Practice, poligy, and theory. Paper presented at the International Consortium for Educational Development Conference, Austin, TX. 
Herreid, C. F., \& Kozak, A. I. (1995). Using students as critics in faculty development. Journal on Excellence in College Teaching, 6(1), 17-29.

Johnson, D. W., Johnson, R. T., \& Smith, K. A. (1991). Active learning: Cooperation in the college classroom. Edina, MN: Interaction.

Kurfiss, J., \& Boice, R. (1990). Current and desired faculty development practices among POD members. To Improve the Academy, 9, 73-82.

McKeachie, W. J. (1991). What theories underlie the practice of faculty development? To Improve the Academy, 10, 3-8.

Morral, F., \& Tonyan, H. (1995). Guidelines for student observers in working with faculy. Northfield, MN: Carleton College Learning and Teaching Center.

Omaha Boy, N. (1998). TEC: Support services. In Rutgers: The State University of New Jersey [Online]. Available: camden-www.rutgers.edu/Camden/TEC/ Services.html

Rallis, H. (1994). Creating teaching and learning partnerships with students: Helping faculty listen to student voices. To Improve the Academy, 13, 255-268.

Redmond, M. V., \& Clark, D. J. (1982). A practical approach to improving teaching. AAHE Bulletin, 34 (6), 8-10.

Richlin, L. (1998). Using CATs to help new instructors develop as teachers. In T. A. Angelo (Ed.), Classroom assessment and research: An update on uses, approaches, and research findings (pp. 79-86). New Directions for Teaching and Learning, No. 75. San Francisco, CA: Jossey-Bass.

Seldin, P. (1997). Using student feedback to improve teaching. To Improve the Academy, 16, 335-346.

Shulman, L. S. (1993, November/December). Teaching as community property: Putting an end to pedagogical solitude. Change, 25 (6), 6-7.

Sorenson, D. L. (1994). Valuing the student voice: Student observer/consultant programs. To Improve the Academy, 13, 97-108.

Sorenson, D. L. (1998a, April). Student observer/consultants: Providing feedback to instructors on teaching. Paper presented at the International Consortium for Educational Development Conference, Austin, TX.

Sorenson, D. L. (1998b, October). Student observers/consultants as collaboralors in instructional development. Paper presented at the Conference of the Professional and Organizational Development Network in Higher Education, Snowbird, UT.

Sorenson, D. L. (1999). Students consulting on teaching: Faculty bandlook. Provo, UT: Brigham Young University Faculty Center. 
Steadman, M. (1998). Using classroom assessment to change both teaching and learning. In T. A. Angelo (Ed.), Classroom assessment and research: An update on uses, approaches, and research findings (pp. 23-35). New Directions for Teaching and Learning, No. 75. San Francisco, CA: Jossey-Bass.

Steadman, M., \& Svinicki, M. (1998). CATs: A student's gateway to better learning. In T. A. Angelo (Ed.), Classroom assessment and research: An update on uses, approaches, and research findings (pp. 13-20). New Directions for Teaching and Learning, No. 75. San Francisco, CA: Jossey-Bass.

Wright, W. A., \& O'Neil, M. C. (1994). Teaching improvement practices: New perspectives. To Improve the Academy, 13, 5-37.

Wright, W. A., \& O'Neil, M. C. (1995). Teaching improvement practices: International perspectives. In W. A. Wright \& Associates (Eds.), Teaching improvement practices: Successful strategies for higher education (pp. 1-57). Bolton, MA: Anker.

Zahorski, K. J. (1993, October). Involving students in faculty development: A matter of value and values. Paper presented at the Conference of the Professional and Organizational Development Network in Higher Education, Rochester, MN.

Contacts:

Milton D. Cox

106 Roudebush

Teaching Effectiveness Programs

Miami University

Oxford, $\mathrm{OH} 45056$

(513) 529-6648

(513) 529-3762 (FAX)

coxmd@muohio.edu

D. Lynn Sorenson

Faculty Center

4450 ELWC

Brigham Young University

Provo, UT 84602

(801) $378-7420$

(801) 378-7467 (FAX)

lynn_sorenson@byu.edu

Milton D. Cox is University Director for Teaching Effectiveness Programs at Miami University, where he founded the annual Lilly Conference on College 
Teaching. He also is Editor-in-Chief of the Journal on Excellence in College Teaching and directs the 1994 Hesburgh Award-winning Teaching Scholars Program. He teaches mathematics and is using Gardner's multiple intelligences and student learning portfolios in his calculus and finite mathematics classes. His current research areas include faculty learning communities.

D. Lynn Sorenson is Assistant Director of the Faculty Center at Brigham Young University, where she coordinates Students Consulting on Teaching (SCOT) among other faculty and instructional development programs. She was previously with the Instructional Development Program at the University of Oklahoma. In addition, for over three decades she has held teaching positions and led teacher development programs for The Church of Jesus Christ of Latter-day Saints. A former member of POD Core, she has served as conference program chair, as conference coordinator and on numerous POD committees. Her research and publications center on new faculty careers and valuing the student voice in teaching development. 


\section{APPENDIX 7.1}

\section{TEACHING SCHOLARS PROGRAM SEMINAR INFORMATION REQUEST}

Dinner Seminar: Sharing Faculty and Student Views of Teaching and Learning

Date and Time: Monday, October 12, 7:00-9:00 p.m.

Place: Bystrom Room, Shriver Center

Please return to Milt by October 7

\section{FACULTY RESPONSE}

Your Name:

\section{My Five Keys to Successful Teaching}

\section{As Viewed by Faculty}

List only one key per item: no run-on sentences slipping in several keys. 1.

2.

3.

4.

5.

My Two "Questions to Students about Teaching and Learning" 1.

2.

$$
\text { My Metaphor for Teaching }
$$

Your student's name:

Why did you select this student?

Please return this and your student's response to Milt Cox, Office for the Advancement of Scholarship and Teaching, by October 7. Thank you. 


\section{APPENDIX 7.2}

\section{Miami University 1998-99 Teaching Scholars Program Seminar: Sharing Student \& Faculty Views of Teaching and Learning: $10 / 12 / 98$}

\begin{tabular}{|c|c|c|}
\hline Keys to Effective Teaching and Learning & $\begin{array}{c}\text { Faculty } \\
\text { Frequency }\end{array}$ & $\begin{array}{l}\text { Student } \\
\text { Frequency }\end{array}$ \\
\hline \multicolumn{3}{|l|}{ Student Relations/Rapport } \\
\hline $\begin{array}{l}\text { Rapport with students: approachable, } \\
\text { friendly, encouraging }\end{array}$ & 1 & 1 \\
\hline Motivate students & & 1 \\
\hline Respect & 1 & 1 \\
\hline Positive, comfortable learning environment & 1 & \\
\hline Caring & 1 & 2 \\
\hline Understanding & & 1 \\
\hline Concern & & 1 \\
\hline Encourage student input & & 1 \\
\hline Subtotals & $4 ; 4$ keys & $8 ; 7$ keys \\
\hline \multicolumn{3}{|l|}{ Professor KNOWLedge/SKILL } \\
\hline Knowledge of subject & 1 & 1 \\
\hline Communication skills & 2 & 3 \\
\hline Listening skill & 1 & \\
\hline Organization/well organized & 1 & \\
\hline Content: for career; up-to-date & 2 & \\
\hline Competent & & 1 \\
\hline Subtotals & $7 ; 5$ keys & $5 ; 3$ keys \\
\hline \multicolumn{3}{|l|}{$\begin{array}{c}\text { CONCRETE IN-Class/OUT-OF-Class } \\
\text { ACTIVITY/Process }\end{array}$} \\
\hline Get students active/interactive learning & 1 & 2 \\
\hline Problem solving & 1 & \\
\hline Experimentation & 1 & \\
\hline Hands on approach & 1 & \\
\hline Teach the basics & & 1 \\
\hline Available/Accessible & 2 & \\
\hline Teach to a variety of learning styles & & 3 \\
\hline Use discussion & & 1 \\
\hline Answer questions effectively & & 1 \\
\hline Use applications of subject & 3 & \\
\hline Use examples & $\frac{2}{2}$ & \\
\hline
\end{tabular}




\begin{tabular}{|c|c|c|}
\hline Keys to Effective Teaching and Learning & \begin{tabular}{|c|} 
Faculty \\
Frequency
\end{tabular} & $\begin{array}{c}\text { Student } \\
\text { Frequency }\end{array}$ \\
\hline Cooperative/collaborative learning & 1 & \\
\hline Use video & 1 & \\
\hline Use case studies & 1 & \\
\hline Subtotals & $15 ; 11$ keys & $7 ; 4$ keys \\
\hline \multicolumn{3}{|l|}{$\begin{array}{c}\text { Abstract (Less Concrete) } \\
\text { InsDide/Outside Class Process }\end{array}$} \\
\hline Relate to real world & 1 & \\
\hline Balance & & 1 \\
\hline Model what you teach, believe & 1 & 1 \\
\hline Stimulate interest & 1 & \\
\hline $\begin{array}{l}\text { Open environment in class, learning } \\
\text { from others }\end{array}$ & 1 & 1 \\
\hline Relevance, make apparent & 1 & \\
\hline Practical: use practical activities to teach & & 1 \\
\hline Subtotals & $5 ; 5$ keys & $4 ; 4$ keys \\
\hline \multicolumn{3}{|l|}{ Personal Qualities of Faculty } \\
\hline Humor/not so serious & 1 & 1 \\
\hline Interesting person & & 1 \\
\hline Open mind & & 1 \\
\hline Flexible/Adaptable & 1 & 2 \\
\hline Fair/unbiased/consistent & 2 & 1 \\
\hline Enthusiasm & 1 & 1 \\
\hline Supportive & & 1 \\
\hline Welcoming & & 1 \\
\hline Subtotals & $5 ; 4$ keys & $9 ; 8$ keys \\
\hline \multicolumn{3}{|l|}{$\begin{array}{c}\text { Course/TeAching Related } \\
\text { Qualities OF FACULTY } \\
\end{array}$} \\
\hline Well prepared & 4 & 2 \\
\hline Clear expectations, clarity & 1 & \\
\hline Enjoy teaching & 1 & 1 \\
\hline High standards & & 1 \\
\hline Connect with one's past learning as student & & 1 \\
\hline Subtotals & $6 ; 3$ keys & $5 ; 4$ keys \\
\hline \multicolumn{3}{|l|}{ OTHER } \\
\hline Colleague interaction about teaching & 1 & \\
\hline Teach small classes & & 1 \\
\hline Subtotals & $1 ; 1 \mathrm{key}$ & $1 ; 1$ key \\
\hline Totals & $43 ; 33$ keys & $39 ; 31$ keys \\
\hline
\end{tabular}




\section{APPENDIX 7.3}

\section{Teacbing and Leaming Questions Raised by Students}

1. What main "drive" keeps you going each day and each year?

2. Why do you think Miami students are so grade oriented?

3. Why aren't effort and time given towards understanding a class taken into consideration (often) in grading?

4. Teaching/learning is a highly beneficial and fulfilling career. What might lead teachers to lose their desire to teach?

5. Have you ever had an extremely synergistic class, and if so, what led to this experience?

6. How often do you change or update your teaching styles?

7. Do you believe college professors should be trained in educational methods as are secondary and elementary teachers?

8. How has technology (e.g., web sites) impacted your teaching methods?

9. Why is it that at the college level all of the strategies and theories taught to education students for K-12 learning are for the most part completely disregarded?

10. Why are college professors not required to take some instruction on how to deliver instruction?

11. How can professors maintain student interest during lectures?

12. What should a teacher do when he/she is not able to answer a question?

13. What central figure is (was) key in shaping your teaching philosophy and your pedagogy?

14. What do you believe is the most important element or key to successful teaching?

\section{Teacbing and Leaming Questions Raised by Faculty}

1. Does reading the content for the class as listed in the syllabus help to focus your reading so you know what to read and what to scan in the reading?

2. What is the most effective method to assist you to comprehend and apply the concepts in the assigned reading?

3. What do you view as a professor's role in the learning process?

4. What are some things that might make you view a professor as a bad teacher? 
5. Should a teacher structure a course in such a way that it mandates certain behaviors (e.g. regular attendance, daily preparation)?

6. Should a professor teach to the lowest level performers in a class, the highest level performers, or somewhere in between?

7. What do you expect to get from lectures?

8. How does one convince students to study systematically?

9. How do you define a good/excellent lecture that is stimulating, challenging, and informative?

10. What can a professor/instructor do to maximize retention and conversion of information/facts to knowledge?

11. How important do you think a good knowledge base is when you think about all the things which you need to be a good teacher?

12. What are the two things you value most in a professor who contributes significantly to your education?

13. What is the most effective way for you to learn theoretical/conceptual information?

14. What is the best teaching practice you've ever encountered? Why?

15. How much effort, dedication, time are you willing to commit to learning this material?

16. How do you know when you have "learned" something?

17. How important is classroom climate?

18. How much authority/flexibility do you expect? 


\section{APPENDIX 7.4}

\section{Miami University Teaching Effectiveness Programs Student Session Chair Protocol Summary}
1. Report to registration desk 20 minutes before your ses-
Before
the sion.
Session
2. Pick up evaluation forms at desk.
Session
3. Arrive 2 minutes before previous session ends.

Getting

Ready

for the

Session

During

the

Session

4-5.Help the previous session chair end the previous session \& collect evaluations.

6-7. Get the room in order and check AV for your session.

8-9. Introduce yourself to your session leader and check signals.

10. Handout/place evaluation forms for your session.

11. Crowd control.

12. Introduce the session leader(s) 1/2 minute after scheduled start.

13- Latecomers: seat and/or encourage them to move on.

14.

15. During the session: enjoy and participate.

Ending

the

Session

16- 3 minutes before scheduled end of session: signal the

17. presenter.

18. 1/2 minute remains: signal again, perhaps stand.

19. Time is up: lead a round of applause.

After

the

Session

20. Collect evaluation forms at door.

21. Thank the leader and give him or her the evaluation carbons.

22. If the next session chair fails to appear, start that session.

23. Return used and unused evaluation forms to registration table.

Thanks!

Nole. The full protocol is available from one of the authors, M. Cox. 